\title{
Calcário, gesso e efeito residual de fertilizantes na produção de biomassa e ciclagem de nutrientes de milheto ${ }^{1}$
}

\author{
Maria da Conceição Santana Carvalho ${ }^{2}$, Adriano Stephan Nascente ${ }^{2}$
}

\section{ABSTRACT}

Limestone, gypsum and residual effect of fertilizers in the biomass production and nutrient cycling of millet plants

Cover crops can provide a higher nutrient cycling. This study aimed to determine the effect of annual applications of gypsum and lime to the soil surface and of fertilizer doses to the previous crop (soybean) in the dry biomass production and nutrient accumulation by plants of pearl millet grown in succession, under no-tillage system. The experimental design was randomized blocks, in a $4 \times 4$ factorial scheme, with four replications. Treatments consisted of the combination of four types of soil conditioner (lime, lime + gypsum, gypsum and control), split in three parts ( $2 \mathrm{t} \mathrm{ha}^{-1}$ of lime and 1,0 tha $\mathrm{th}^{-1}$ of gypsum; $2 \mathrm{t} \mathrm{ha}^{-1}$ of lime and $1 \mathrm{t} \mathrm{ha}^{-1}$ of gypsum; and $1 \mathrm{tha}^{-1}$ of lime and $0.5 \mathrm{tha}^{-1}$ of gypsum), and four fertilizing rates with $\mathrm{P}$ (triple and simple superphosphate) and $\mathrm{K}$ (potassium chloride) $(0 \%, 50 \%, 100 \%$ and $150 \%$ of the recommended fertilizing), applied at the sowing of the previous crop (soybean). Liming provided increments in the dry biomass production and in the accumulation of nutrients $(\mathrm{N}, \mathrm{P}, \mathrm{K}$, $\mathrm{Ca}, \mathrm{Mg}$ and S) by millet plants. The application of gypsum did not increase the millet dry biomass yield. The use of increasing rates of fertilizers in the previous crop (soybean) increased the biomass dry matter, density and accumulation of nutrients by millet plants. The intercropping of millet as a cover crop, with the residual effect of the fertilizer applied in the summer crop, provided a nutrient cycling that can be used by the following crops.

KEY-WORDS: Pennisetum glaucum (L.) R. Brown; Glycine max (L.) Merr; mineral nutrition; Brazilian Savannah.

\section{INTRODUÇÃO}

O sistema plantio direto (SPD) é uma técnica que possibilita diversos benefícios ambientais, pois aumenta os teores de matéria orgânica e a atividade biológica do solo, reduz as oscilações de temperatura do solo, diminui a erosão laminar, bem como o carreamento de fertilizantes e agrotóxicos para os mananciais de água, reduz a densidade populacional de plantas daninhas

\section{RESUMO}

Plantas de cobertura podem proporcionar maior ciclagem de nutrientes. O trabalho objetivou determinar o efeito da aplicação anual de gesso e calcário à superfície do solo e de doses de fertilizantes à cultura anterior (soja), na produção de biomassa seca e no acúmulo de nutrientes por plantas de milheto cultivadas em sucessão, sob sistema plantio direto. $\mathrm{O}$ delineamento experimental foi em blocos casualizados, em esquema fatorial $4 \times 4$, com quatro repetições. Os tratamentos consistiram da combinação de quatro tipos de condicionadores de solo (calcário, calcário + gesso, gesso e controle), parcelados em três partes $\left(2 \mathrm{tha} \mathrm{a}^{-1}\right.$ de calcário e $1,0 \mathrm{tha}^{-1}$ de gesso; $2 \mathrm{t} \mathrm{ha}^{-1}$ de calcário e 1,0 tha $a^{-1}$ de gesso; e $1 \mathrm{t} \mathrm{ha}^{-1}$ de calcário e $0,5 \mathrm{t} \mathrm{ha}^{-1}$ de gesso), com quatro níveis de adubação com $\mathrm{P}$ (superfosfato simples e triplo) e K (cloreto de potássio) $(0 \%, 50 \%, 100 \%$ e $150 \%$ da adubação recomendada), aplicados na semeadura da cultura anterior (soja). O calcário proporcionou incrementos na produção de biomassa seca e no acúmulo de nutrientes $(\mathrm{N}, \mathrm{P}, \mathrm{K}$ $\mathrm{Ca}, \mathrm{Mg}$ e S), pelas plantas de milheto. $\mathrm{O}$ gesso não proporcionou alterações na produção de biomassa seca do milheto. A utilização de doses crescentes de fertilizantes na cultura anterior (soja) aumentou a produção de biomassa seca, concentração e acúmulo de nutrientes nas plantas de milheto. O emprego do milheto como planta de cobertura, na entressafra, utilizando o efeito residual do fertilizante aplicado à cultura de verão, proporcionou ciclagem de nutrientes que pode ser utilizada pela cultura em sucessão.

PALAVRAS-CHAVE: Pennisetum glaucum (L.) R. Brown; Glycine max (L.) Merr; nutrição mineral; Cerrado.

e possibilita maior conservação da umidade do solo, sendo, portanto, considerado sistema de produção sustentável (Mauli et al. 2011, Nascente et al. 2011). O SPD teve crescimento mundial significativo e é, atualmente, empregado em quase 117 milhões de hectares (FAO 2012), sendo que, no Brasil, a área estimada é de 25 milhões de hectares (Nascente et al. 2013a).

No SPD, a formação de camada de palha na superfície do solo, antes da implantação da cultura

1. Trabalho recebido em dez./2013 e aceito para publicação em nov./2014 ( $\mathrm{n}^{\mathrm{o}}$ registro: PAT 27597).

2. Empresa Brasileira de Pesquisa Agropecuária (Embrapa Arroz e Feijão), Santo Antônio de Goiás, GO, Brasil.

E-mails: maria.carvalho@embrapa.br, adriano.nascente@embrapa.br. 
principal, é requisito fundamental (Alvarenga et al. 2001, Pacheco et al. 2011). Entretanto, os resíduos produzidos pelas culturas comerciais geralmente são insuficientes para boa cobertura do solo. Dessa forma, faz-se necessário introduzir plantas com potencial para produzir quantidade de matéria seca de modo que o solo permaneça coberto o maior tempo possível, para a implantação da próxima cultura (Torres et al. 2008, Pacheco et al. 2011, Crusciol et al. 2012).

Assim, a busca por culturas alternativas, que possam deixar sobre o solo camada de palha com quantidade, qualidade e distribuição uniformes, tem se tornado o tema de diversas pesquisas (Pacheco et al. 2011, Costa et al. 2012, Crusciol et al. 2012, Ferrari Neto et al. 2012, Nascente \& Crusciol 2012). Nesses trabalhos, verifica-se algumas opções, como o milheto, apontado como uma das culturas responsáveis pela expansão do SPD, na Região Central do Brasil (Salton \& Kichel 1997). Outra alternativa para o produtor manter a área coberta sem custos seria a utilização da vegetação espontânea (plantas daninhas). No entanto, essas plantas possuem crescimento desuniforme, devido à composição variada de espécies, e mal distribuído no solo. Além disso, se não forem adequadamente controladas, podem competir por água, luz e nutrientes, causando redução na produtividade de grãos das culturas, servir de hospedeiras de pragas e doenças, dificultar as operações de colheita e, caso completem o ciclo, reinfestar a área (Favero et al. 2000, Nascente et al. 2004 e 2013c), não sendo, portanto, prática recomendada o uso do pousio para a formação de palhada em SPD.

Plantas de cobertura como o milheto, semeado em safrinha no Cerrado, podem ser utilizadas para a formação de palha em SPD (Aita \& Giacomini 2003, Boer et al. 2007, Torres et al. 2008). Assim, a cultura que vier em sucessão, cultivada no inverno ou no próximo verão, poderá ser beneficiada por essa camada de palha e, também, pela liberação dos nutrientes advindos da degradação da palha de milheto (Nascente et al. 2013b). Além disso, normalmente, esse milheto cultivado na entressafra não é adubado e aproveita o resíduo da adubação realizada na cultura de verão.

Apesar de existirem diversos trabalhos, nos quais se relata a importância do milheto como planta de cobertura, devido à ciclagem de nutrientes (Boer et al. 2007), poucos são aqueles em que se avaliou o efeito da adubação residual realizada na cultura de verão sobre o milheto. Além disso, em áreas sob
SPD, na Região dos Cerrados, é comum a aplicação de gesso e calcário à superfície do solo sem incorporação, visando à redução da acidez no perfil do solo (Caires et al. 2008, Silva \& Lemos 2008). Nesse sentido, também são raros os trabalhos que avaliam o efeito desses corretivos na produção de biomassa seca e nutrição de plantas em milheto.

Assim, o trabalho objetivou determinar o efeito da aplicação anual de gesso e calcário à superfície do solo sem incorporação e de doses de fertilizantes à cultura anterior (soja), no acúmulo de nutrientes e produção de biomassa seca por plantas de milheto cultivadas em sucessão, em SPD.

\section{MATERIAL E MÉTODOS}

O experimento foi conduzido na Fazenda Capivara da Embrapa Arroz e Feijão, localizada no município de Santo Antônio de Goiás (GO) (16 $28^{\circ} 00^{\prime}$ 'S, 49 $17^{\prime} 00^{\prime \prime} W$ e 823 m de altitude), em 2012 e 2013 . O clima da região é tropical de savana, sendo considerado do tipo Aw, segundo a classificação de Köppen. Há duas estações bem definidas: normalmente seca de maio a setembro (outono/inverno) e chuvosa de outubro a abril (primavera/verão). A precipitação média anual é de 1.500-1.700 mm e a temperatura média anual de $22,7^{\circ} \mathrm{C}$, variando anualmente de $14,2^{\circ} \mathrm{C}$ a $34,8^{\circ} \mathrm{C}$. Adicionalmente, foi feito o monitoramento diário da temperatura e precipitação (Figura 1).

A área experimental foi cultivada por cinco anos em SPD, com milho no verão e feijão no inverno. O solo foi classificado como Latossolo Vermelho ácrico, com textura argilosa. Antes da instalação do experimento, em 2010, foi realizada análise química, às profundidades de $0-0,20 \mathrm{~m}$ e 0,20-0,40 $\mathrm{m}$, para caracterização da área experimental e cálculo da necessidade de calagem e gessagem (Tabela 1).

As análises químicas foram realizadas de acordo com metodologia proposta por Claessen (1997). Assim, o P e o K foram extraídos pelo extrator Mehlich 1 e os elementos $\mathrm{Ca}, \mathrm{Mg}$ e $\mathrm{Al}$ com $\mathrm{KCl}$ $1 \mathrm{M}$. Na solução extraída, o P foi determinado por colorimetria, o K por fotometria de chama, o Ca e $\mathrm{Mg}$ por titulação de EDTA e o Al por titulação de $\mathrm{NaOH}$. Os micronutrientes foram determinados no extrato Mehlich 1 por absorção atômica e a matéria orgânica pelo método de Walkley \& Black.

O delineamento experimental utilizado foi em blocos casualizados, em esquema fatorial $4 \mathrm{x} 4$, com quatro repetições. Os tratamentos consistiram da 

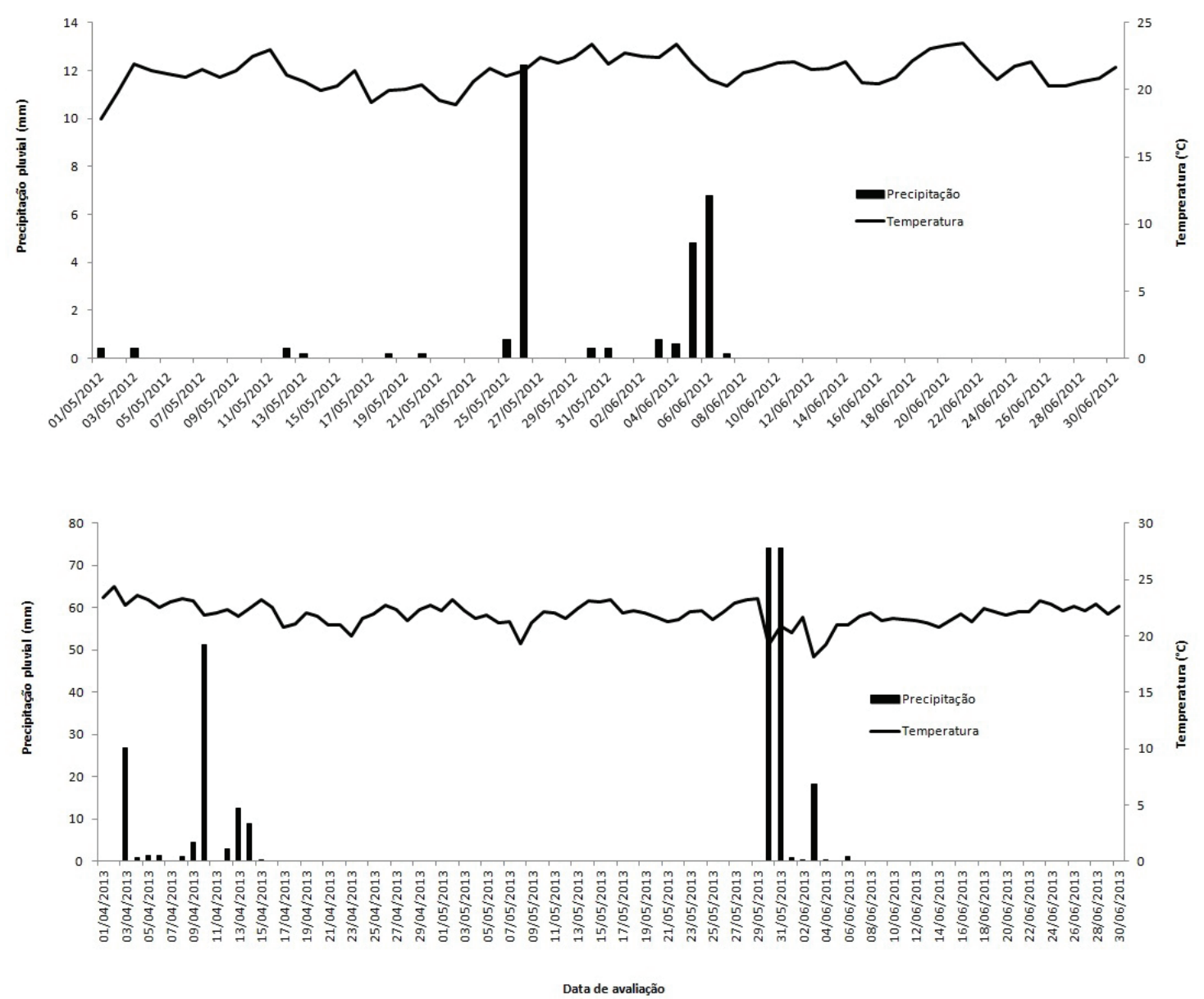

Figura 1. Precipitação pluvial e temperatura média do ar, durante a condução do experimento (Santo Antônio de Goiás, GO, safras 2012 e 2013).

Tabela 1. Características químicas do solo da área, antes da instalação do experimento (Santo Antônio de Goiás, GO, 2010).

\begin{tabular}{|c|c|c|c|c|c|c|c|c|c|c|c|c|c|c|}
\hline Profundidade & $\mathrm{Ca}$ & $\mathrm{Mg}$ & $\mathrm{Al}$ & $\mathrm{H}+\mathrm{Al}$ & $\mathrm{K}$ & CTC & \multirow{2}{*}{$\begin{array}{c}\mathrm{pH} \\
\left(\mathrm{H}_{2} \mathrm{O}\right)\end{array}$} & \multirow{2}{*}{$\begin{array}{l}\mathrm{V} \\
\%\end{array}$} & \multirow{2}{*}{$\frac{\mathrm{MO}}{\mathrm{g} \mathrm{dm}^{-3}}$} & P (Mehlich) & $\mathrm{Zn}$ & $\mathrm{Cu}$ & $\mathrm{Fe}$ & $\mathrm{Mn}$ \\
\hline $\mathrm{cm}$ & 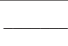 & 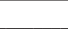 & $-\mathrm{cm}$ & $l_{c} \mathrm{dm}^{-3}$ & & & & & & \multicolumn{5}{|c|}{$\mathrm{mg} \mathrm{dm}^{-3}$} \\
\hline $0-20$ & 0,72 & 0,37 & 0,38 & 6,5 & 0,16 & 7,78 & 5,0 & 16,0 & 18,3 & 6,0 & 3,1 & 2,1 & 58,7 & 11,7 \\
\hline $20-40$ & 0,53 & 0,17 & 0,42 & 7,1 & 0,14 & 7,94 & 4,8 & 10,6 & 17,0 & 2,3 & 2,1 & 1,3 & 38,6 & 6,5 \\
\hline
\end{tabular}

combinação de quatro tipos de correção e/ou condicionamento do solo (calcário, calcário + gesso, gesso e controle - sem aplicação de gesso ou calcário) com quatro níveis de adubação [0\%, 50\%, 100\% e 150\% da adubação recomendada para a cultura (Sousa \& Lobato 2004)], aplicados à cultura anterior (soja). A adubação recomendada correspondeu à aplicação de $80 \mathrm{~kg} \mathrm{ha}^{-1}$ de $\mathrm{P}_{2} \mathrm{O}_{5}(55 \%$ de superfosfato simples e $45 \%$ de superfosfato triplo) e $80 \mathrm{~kg} \mathrm{ha}^{-1}$ de $\mathrm{K}_{2} \mathrm{O}$ (cloreto de potássio). A dose de calcário $\left(5,0 \mathrm{t} \mathrm{ha}^{-1}\right)$ foi calculada para elevar a saturação por bases a $70 \%$, na camada de 0-20 $\mathrm{cm}$ de profundidade. A quantidade de gesso agrícola utilizada $\left(2,5 \mathrm{tha}^{-1}\right)$ foi determinada em função do teor de argila do solo $\left(500 \mathrm{~g} \mathrm{~kg}^{-1}\right)$, à profundidade de 0,20-0,40 $\mathrm{m}$ (Sousa \& Lobato 2004). Esses produtos foram aplicados a lanço na superfície do solo, sem incorporação nos tratamentos correspondentes, parcelados em três partes: em 13/11/2010 ( $2 \mathrm{t} \mathrm{ha}^{-1}$ de calcário e 1,0 t ha-1 de gesso), $11 / 11 / 2011$ ( $2 \mathrm{t} \mathrm{ha}^{-1}$ de calcário e $1,0 \mathrm{t} \mathrm{ha}^{-1}$ de gesso) e $19 / 10 / 2012$ ( $1 \mathrm{t} \mathrm{ha}^{-1}$ de calcário e $0,5 \mathrm{t} \mathrm{ha}^{-1}$ de gesso). O calcário utilizado apresentava $36,4 \%$ de $\mathrm{CaO}, 12 \%$ de $\mathrm{MgO}$ e PRNT de $86,56 \%$, e o gesso $21,8 \%$ de $\mathrm{Ca}$ e $17,4 \%$ de $\mathrm{S}$. 
A semeadura do milheto (cultivar ADR 500) foi realizada mecanicamente em 02/05/2012 e $05 / 04 / 2013$, oito dias após a colheita da cultura da soja. A produtividade da soja foi de $1.490 \mathrm{~kg} \mathrm{ha}^{-1}$, $1.899 \mathrm{~kg} \mathrm{ha}^{-1}, 2.459 \mathrm{~kg} \mathrm{ha}^{-1}$ e $2.659 \mathrm{~kg} \mathrm{ha}^{-1}$, na safra $2011 / 2012$, e $2.674 \mathrm{~kg} \mathrm{ha}^{-1}, 3.083 \mathrm{~kg} \mathrm{ha}^{-1}$, $3.228 \mathrm{~kg} \mathrm{ha}^{-1}$ e $3.382 \mathrm{~kg} \mathrm{ha}^{-1}$, na safra $2012 / 2013$, respectivamente para as doses de $0 \%, 50 \%, 100 \%$ e $150 \%$ da adubação recomendada (Carvalho \& Nascente 2014). O espaçamento utilizado foi de $0,45 \mathrm{~m}$ entrelinhas, utilizando-se $20 \mathrm{~kg}$ de sementes viáveis por hectare. Cada parcela foi constituída por 10 linhas de 5,0 m de comprimento, sendo a área útil as 8 linhas centrais, desprezando-se $0,5 \mathrm{~m}$ das extremidades. Foi utilizado intervalo de 2,0 $\mathrm{m}$ entre as parcelas.

A emergência das plântulas ocorreu aos seis e quatro dias após a semeadura, respectivamente nos anos 2012 e 2013. Não foi realizada adubação de semeadura nem de cobertura na cultura, bem como nenhum tipo de trato cultural no milheto.

Aos 39 dias após a emergência (DAE), na safra 2012, e aos 52 DAE, na safra 2013, o milheto foi dessecado, para a realização da semeadura do feijoeiro comum em sucessão. Nesse momento, foram realizadas amostragens para avaliação da produção de biomassa seca, teor e conteúdo de nutrientes nas plantas de milheto, em três pontos de cada unidade experimental, utilizando-se quadrado metálico vaza-

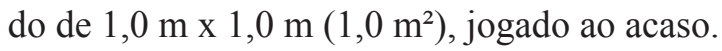

O material vegetal foi coletado rente ao solo, colocado em sacos de papel e seco em estufa com ventilação forçada a $65^{\circ} \mathrm{C}$, até obtenção de massa constante. Em seguida, foi pesado, para se obter a biomassa seca, sendo os valores extrapolados para $\mathrm{kg} \mathrm{ha}^{-1}$. Do material seco de cada parcela, retirou-se uma amostra representativa de $100 \mathrm{~g}$, que foi moída e submetida à análise para determinação dos teores de macronutrientes (N, P, K, Ca, Mg e S) (Malavolta et al. 1997). O N foi analisado por meio de digestão a quente da matéria orgânica, com uma mistura de ácido sulfúrico e agentes catalisadores $(\mathrm{Cu}$ e $\mathrm{Se})$ (micro-Kjeldahl), e submetido a posterior determinação do $\mathrm{N}$ amoniacal formado por destilação a vapor, seguida de titulação com solução padronizada de $\mathrm{H}_{2} \mathrm{SO}_{4}$. Os demais nutrientes foram extraídos por digestão nitro-perclórica, sendo que o $\mathrm{Ca}$ e $\mathrm{Mg}$ foram determinados por espectrometria de absorção atômica, o K por fotometria de chama de emissão, o S por turbidimetria e o $\mathrm{P}$ por colorimetria em espectrofotômetro, pelo método do vanado-molibdato de amônio. Com os dados de produção de biomassa seca, efetuou-se a multiplicação com os teores dos nutrientes $\left(\mathrm{g} \mathrm{kg}^{-1}\right)$ nessa biomassa e calculou-se o conteúdo de nutrientes $\left(\mathrm{kg} \mathrm{ha}^{-1}\right)$ na biomassa seca do milheto.

Os dados obtidos foram submetidos à análise de variância e as médias comparadas pelo teste Tukey $(\mathrm{p}<0,05)$. Para os dados quantitativos (níveis de adubação), procedeu-se à análise de regressão. Para essas análises, utilizou-se o programa estatístico SAS.

\section{RESULTADOS E DISCUSSÃO}

Verificou-se que, de maneira geral, os efeitos da adubação e calagem foram pouco expressivos, na concentração de nutrientes nas plantas de milheto (Tabela 2). Na primeira safra (2012), observou-se que houve efeito dos corretivos e/ou condicionadores de solo nos teores de $\mathrm{Ca}$ e $\mathrm{S}$, na biomassa seca das plantas de milheto. A aplicação de calcário com ou sem gesso reduziu os teores de cálcio, enquanto, para o $\mathrm{S}$, verificou-se maiores valores nos tratamentos em que se aplicou gesso. Como houve aumento na disponibilidade de Ca no solo, com a aplicação de calcário (Carvalho \& Nascente 2014), a redução dos teores de Ca no milheto pode ser explicada pelo efeito de diluição do nutriente nos tecidos da planta, devido ao maior crescimento das plantas e ao aumento de cerca de $40 \%$ na produção de biomassa seca, em comparação com o tratamento controle (Tabela 3).

Na segunda safra (2013), ocorreu efeito nos teores de $\mathrm{Mg}$ e S, na biomassa seca do milheto. Onde se aplicou calcário, foram observados os maiores valores de $\mathrm{Mg}$, refletindo no baixo teor de $\mathrm{Mg}$ encontrado no solo antes do início do experimento (Tabela 1) e no aumento da disponibilidade desse nutriente, pela aplicação do calcário dolomítico que continha $12 \%$ de $\mathrm{MgO}$. A ocorrência desse efeito apenas no segundo ano deve estar associada ao aumento da disponibilidade de $\mathrm{Mg}$ no solo, com a aplicação da segunda parcela de calcário, e à exportação acumulada de $\mathrm{Mg}$ nos grãos, nas duas safras.

O gesso continha $17,4 \%$ de $\mathrm{S}$, fato que, provavelmente, aumentou sua disponibilidade no solo, e as plantas de milheto o absorveram em maior quantidade, corroborando os resultados obtidos em trabalhos com a aplicação de gesso, nas culturas do algodão (Silva et al. 1997), milho (Carvalho \& Raij 1997) e soja (Caires et al. 1988 e 2003, Quaggio et al. 1993), e confirmando que o gesso é excelente 
Tabela 2. Concentração de N, P, K, Ca, Mg e S na biomassa seca do milheto, aos 39 (safra 2012) e 52 (safra 2013) dias após a emergência sob SPD, afetadas pela aplicação de calcário e/ou gesso e níveis de adubação aplicados à cultura anterior (soja) (Santo Antônio de Goiás, GO).

\begin{tabular}{|c|c|c|c|c|c|c|}
\hline \multirow{3}{*}{ Corretivo/Condicionador } & \multicolumn{6}{|c|}{ Safra 2012} \\
\hline & $\mathrm{N}$ & $\mathrm{P}$ & $\mathrm{K}$ & $\mathrm{Ca}$ & $\mathrm{Mg}$ & $\mathrm{S}$ \\
\hline & \multicolumn{6}{|c|}{$\mathrm{g} \mathrm{kg}^{-1}$} \\
\hline Testemunha & $16,4 a^{*}$ & $1,86 \mathrm{a}$ & $14,2 \mathrm{a}$ & $3,17 \mathrm{a}$ & $1,75 \mathrm{a}$ & $1,48 \mathrm{~b}$ \\
\hline Calcário & $16,5 \mathrm{a}$ & $1,91 \mathrm{a}$ & $12,5 \mathrm{a}$ & $2,68 \mathrm{~b}$ & $2,04 \mathrm{a}$ & $1,51 \mathrm{~b}$ \\
\hline Calcário + gesso & $16,5 \mathrm{a}$ & $1,88 \mathrm{a}$ & $13,3 \mathrm{a}$ & $2,64 \mathrm{~b}$ & $1,77 \mathrm{a}$ & $1,87 \mathrm{a}$ \\
\hline Gesso & $17,0 \mathrm{a}$ & $1,86 \mathrm{a}$ & $14,3 \mathrm{a}$ & $3,04 \mathrm{ab}$ & $1,81 \mathrm{a}$ & $1,76 \mathrm{a}$ \\
\hline \multicolumn{7}{|l|}{ Nível de adubação } \\
\hline 0,0 & 17,7 & 1,78 & 13,1 & 2,96 & 1,69 & 1,62 \\
\hline 0,5 & 16,1 & 1,74 & 14,5 & 2,84 & 1,94 & 1,51 \\
\hline 1,0 & 15,7 & 1,91 & 12,9 & 2,93 & 1,95 & 1,68 \\
\hline 1,5 & 16,9 & 2,06 & 13,9 & 2,81 & 1,79 & 1,80 \\
\hline Fontes de variação & \multicolumn{6}{|c|}{ Probabilidade do teste $\mathrm{F}$} \\
\hline Corretivo e/ou condicionador (C) & 0,9505 & 0,9898 & 0,2604 & 0,0030 & 0,2640 & 0,0019 \\
\hline Adubação (Ad) & 0,2813 & 0,2475 & 0,3588 & 0,7612 & 0,3466 & 0,0804 \\
\hline $\mathrm{C} \times \mathrm{Ad}$ & 0,8144 & 0,9820 & 0,0856 & 0,4552 & 0,8144 & 0,3773 \\
\hline Corretivo/Condicionador & \multicolumn{6}{|c|}{ Safra 2013} \\
\hline Testemunha & $18,43 \mathrm{a}$ & $1,57 \mathrm{a}$ & $27,21 \mathrm{a}$ & $3,80 \mathrm{a}$ & $1,51 \mathrm{~b}$ & $1,35 \mathrm{~b}$ \\
\hline Calcário & $18,80 \mathrm{a}$ & $1,57 \mathrm{a}$ & $24,34 \mathrm{a}$ & 3,46 a & $1,81 \mathrm{a}$ & $1,26 \mathrm{~b}$ \\
\hline Calcário + gesso & $17,98 \mathrm{a}$ & $1,54 \mathrm{a}$ & $26,01 \mathrm{a}$ & $4,00 \mathrm{a}$ & $1,76 a b$ & $1,56 \mathrm{a}$ \\
\hline Gesso & $18,26 \mathrm{a}$ & $1,68 \mathrm{a}$ & $27,78 \mathrm{a}$ & $3,89 \mathrm{a}$ & $1,80 \mathrm{ab}$ & $1,63 \mathrm{a}$ \\
\hline \multicolumn{7}{|l|}{ Nível de adubação } \\
\hline 0,0 & 18,12 & 1,26 & 22,90 & 3,73 & 1,36 & 1,36 \\
\hline 0,5 & 18,76 & 1,64 & 26,39 & 3,75 & 1,77 & 1,37 \\
\hline 1,0 & 17,70 & 1,68 & 27,11 & 3,78 & 1,80 & 1,45 \\
\hline 1,5 & 18,90 & 1,79 & 28,93 & 3,89 & 1,96 & 1,63 \\
\hline Fontes de variação & \multicolumn{6}{|c|}{ Probabilidade do teste $\mathrm{F}$} \\
\hline Corretivo e/ou condicionador (C) & 0,7974 & 0,8118 & 0,0781 & 0,1156 & 0,0249 & $<0,0010$ \\
\hline Adubação (Ad) & 0,4452 & 0,0047 & 0,0008 & 0,8963 & $<0,0010$ & 0,0008 \\
\hline $\mathrm{C} \times \mathrm{Ad}$ & 0,5640 & 0,9679 & 0,1883 & 0,2965 & 0,2614 & 0,0522 \\
\hline
\end{tabular}

* Médias seguidas de mesma letra, na coluna, não diferem entre si pelo teste Tukey, a 5\%.

fonte desse nutriente. Resultados semelhantes foram relatados por Rosolem \& Marcello (1998), em soja sob SPD, Costa \& Rosolem (2007), em rotação de trigo e soja sob SPD, e Veronese et al. (2012), com plantas de cobertura sob SPD, os quais observaram que a calagem proporcionou aumento nos teores de nutrientes nas plantas. Entretanto, no presente trabalho, verificou-se pequena variação devido à aplicação de calcário, o que pode ser reflexo de alguns fatores, como, por exemplo, efeito de diluição pelo maior crescimento das plantas, período curto de cultivo do milheto, com menor tempo para absorção de nutrientes, e efeito residual da adubação realizada nas culturas anteriores, que proporcionaram boa nutrição para as plantas de milheto.

Os níveis de adubação não proporcionaram alterações nos teores de nutrientes na biomassa seca das plantas de milheto, na safra 2012, provavelmente devido ao reduzido período de desenvolvimento das plantas (39 DAE), o qual não foi suficiente para proporcionar diferenças na absorção de nutrientes, devido à aplicação de doses maiores de fertilizantes à cultura anterior. Por outro lado, na safra 2013, afetaram os teores de $\mathrm{P}, \mathrm{K}, \mathrm{Mg}$ e S (Figura 2), que tiveram ajustes quadráticos.

Nessa segunda safra (2013), as plantas de milheto cresceram e se desenvolveram por período superior (52 DAE), o que possibilitou detectar diferenças na absorção dos nutrientes. Os maiores teores de $\mathrm{Pe} \mathrm{K}$ podem ter resultado das maiores quantidades desses nutrientes aplicados à soja, e o de enxofre da maior aplicação de superfosfato simples, que contém, em sua fórmula, $8 \%$ do elemento.

$\mathrm{O}$ aumento da absorção de $\mathrm{Mg}$ pode ter resultado de uma interação positiva entre o $\mathrm{Pe} \mathrm{o} \mathrm{Mg}$ (efeito sinergético). Assim, o aumento da disponibilidade de P no solo, com a elevação no nível de adubação, conforme mostrado por Carvalho \& Nascente (2014), provavelmente, proporcionou aumento na absorção de $\mathrm{Mg}$ pelas plantas de milheto, com efeito significa- 

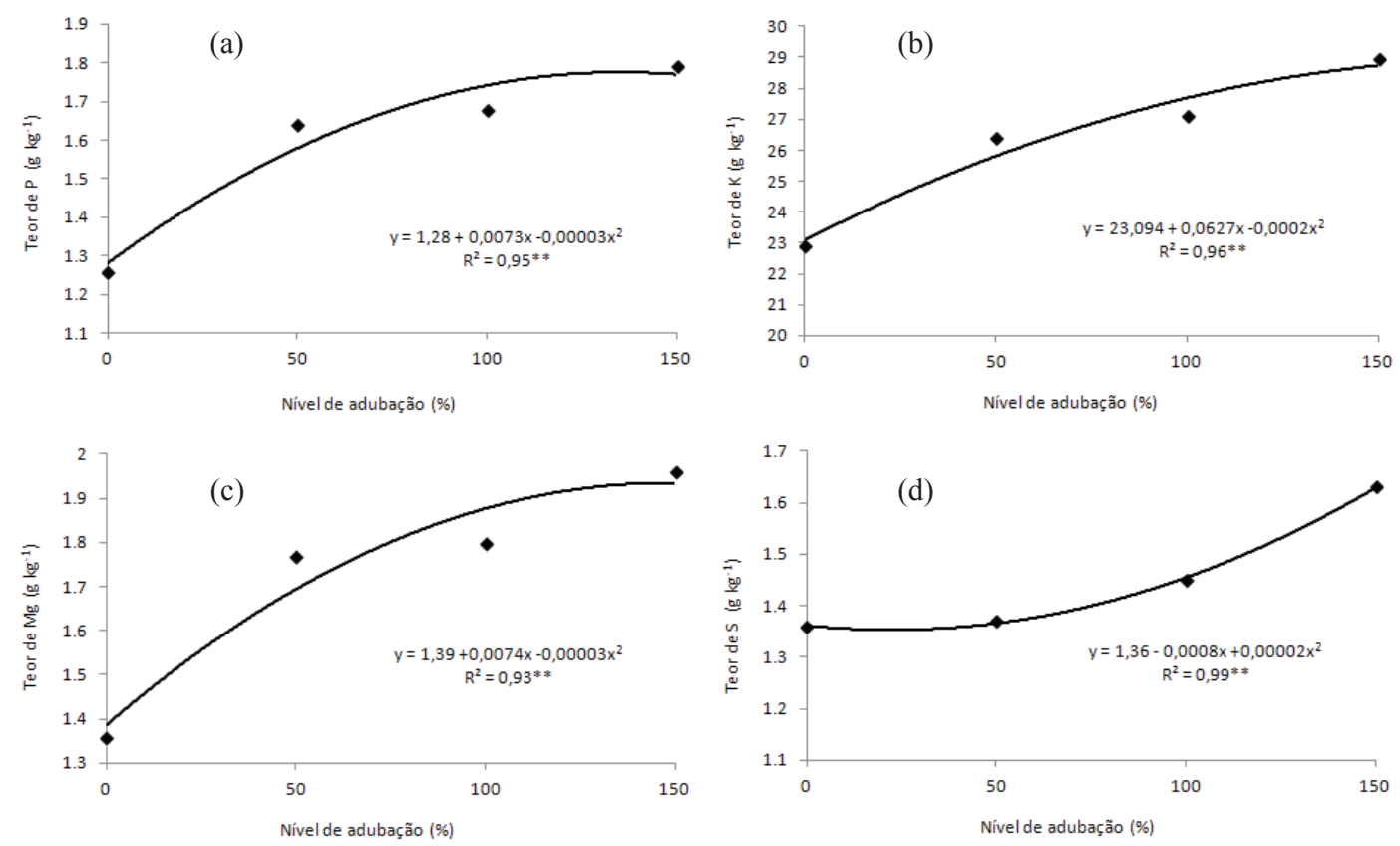

Figura 2. Teores de P (a), K (b), Mg (c) e S (d) na biomassa seca de plantas de milheto, em função dos níveis de adubação aplicados à cultura anterior (soja) (Santo Antônio de Goiás, GO, safra 2013).

Tabela 3. Produção de biomassa seca (BS) e acúmulo de N, P, K, Ca, Mg e S nessa biomassa, aos 39 (safra 2012 ) e 52 (safra 2013) dias após a emergência do milheto sob SPD, afetados pela aplicação de calcário e/ou gesso e níveis de fertilizantes aplicados à cultura anterior (soja) (Santo Antônio de Goiás, GO).

\begin{tabular}{|c|c|c|c|c|c|c|c|}
\hline \multirow{3}{*}{ Corretivo/Condicionador } & \multicolumn{7}{|c|}{ Safra 2012} \\
\hline & $\mathrm{BS}$ & $\mathrm{N}$ & $\mathrm{P}$ & $\mathrm{K}$ & $\mathrm{Ca}$ & $\mathrm{Mg}$ & $\mathrm{S}$ \\
\hline & \multicolumn{7}{|c|}{$-\mathrm{kg} \mathrm{ha}^{-1}$} \\
\hline Testemunha & $1.734 b^{*}$ & $27,83 \mathrm{bc}$ & $3,31 \mathrm{~b}$ & $25,36 \mathrm{a}$ & $5,48 \mathrm{a}$ & $2,98 \mathrm{~b}$ & $2,65 \mathrm{c}$ \\
\hline Calcário & $2.494 \mathrm{a}$ & $40,77 \mathrm{a}$ & $4,75 \mathrm{a}$ & $31,36 \mathrm{a}$ & $6,68 \mathrm{a}$ & $5,21 \mathrm{a}$ & $3,88 \mathrm{ab}$ \\
\hline Calcário + gesso & $2.374 \mathrm{a}$ & $37,87 \mathrm{ab}$ & $4,36 a b$ & $32,23 \mathrm{a}$ & $6,23 \mathrm{a}$ & $4,21 \mathrm{ab}$ & $4,41 \mathrm{a}$ \\
\hline Gesso & $1.870 \mathrm{~b}$ & $30,67 \mathrm{c}$ & $3,48 \mathrm{ab}$ & $26,00 \mathrm{a}$ & $5,59 \mathrm{a}$ & $3,44 \mathrm{~b}$ & $3,25 \mathrm{bc}$ \\
\hline \multicolumn{8}{|l|}{ Nível de adubação } \\
\hline 0,0 & 1.368 & 23,40 & 2,43 & 17,39 & 3,94 & 2,27 & 2,28 \\
\hline 0,5 & 2.193 & 35,33 & 3,81 & 31,59 & 6,11 & 4,24 & 3,36 \\
\hline 1,0 & 2.401 & 36,67 & 4,53 & 30,45 & 6,91 & 4,73 & 4,01 \\
\hline 1,5 & 2.511 & 41,75 & 5,13 & 35,53 & 7,02 & 4,59 & 4,53 \\
\hline Fontes de variação & \multicolumn{7}{|c|}{ Probabilidade do teste $\mathrm{F}$} \\
\hline Corretivo e/ou condicionador (C) & 0,0002 & 0,0012 & 0,0150 & 0,1334 & 0,0923 & 0,0003 & $<0,0010$ \\
\hline Adubação (Ad) & $<0,0010$ & $<0,0010$ & $<0,0010$ & $<0,0010$ & $<0,0010$ & $<0,0010$ & $<0,0010$ \\
\hline $\mathrm{C} \times \mathrm{Ad}$ & 0,8851 & 0,5892 & 0,9158 & 0,6606 & 0,8608 & 0,7361 & 0,7719 \\
\hline Corretivo/Condicionador & \multicolumn{7}{|c|}{ Safra 2013} \\
\hline Testemunha & $2.732 \mathrm{~b}$ & $50,75 \mathrm{a}$ & $4,44 \mathrm{a}$ & $73,75 \mathrm{a}$ & $10,38 \mathrm{~b}$ & $4,14 \mathrm{~b}$ & $3,71 \mathrm{~b}$ \\
\hline Calcário & $3.225 \mathrm{a}$ & $60,10 \mathrm{a}$ & $5,14 \mathrm{a}$ & $80,42 \mathrm{a}$ & $11,24 \mathrm{ab}$ & $5,86 \mathrm{a}$ & $4,09 \mathrm{~b}$ \\
\hline Calcário + gesso & $3.290 \mathrm{a}$ & $58,88 \mathrm{a}$ & $5,15 \mathrm{a}$ & $86,24 \mathrm{a}$ & $13,12 \mathrm{a}$ & $5,84 \mathrm{a}$ & $5,10 \mathrm{a}$ \\
\hline Gesso & $2.770 \mathrm{~b}$ & $50,52 \mathrm{a}$ & $4,83 \mathrm{a}$ & $77,31 \mathrm{a}$ & $10,78 \mathrm{ab}$ & $4,95 \mathrm{ab}$ & $4,62 \mathrm{ab}$ \\
\hline \multicolumn{8}{|l|}{ Nível de adubacão } \\
\hline 0,0 & 2.479 & 44,51 & 3,08 & 56,54 & 9,25 & 3,31 & 3,40 \\
\hline 0,5 & 3.051 & 57,48 & 5,13 & 80,27 & 11,53 & 5,44 & 4,16 \\
\hline 1,0 & 3.135 & 55,37 & 5,39 & 84,30 & 11,73 & 5,62 & 4,55 \\
\hline 1,5 & 3.351 & 62,88 & 5,97 & 96,61 & 13,01 & 6,43 & 5,42 \\
\hline Fontes de variação & \multicolumn{7}{|c|}{ Probabilidade do teste $\mathrm{F}$} \\
\hline Corretivo e/ou condicionador (C) & 0,0099 & 0,0586 & 0,6879 & 0,1596 & 0,0345 & $<0,0010$ & 0,0016 \\
\hline Adubação (Ad) & 0,0007 & 0,0010 & 0,0006 & $<0,0010$ & 0,0035 & $<0,0010$ & $<0,0010$ \\
\hline $\mathrm{C} \times \mathrm{Ad}$ & 0,8594 & 0,7334 & 0,9834 & 0,0523 & 0,4214 & 0,2460 & 0,2260 \\
\hline
\end{tabular}

* Médias seguidas de mesma letra, na coluna, não diferem entre si pelo teste Tukey, a $5 \%$. 
tivo no segundo ano, devido ao maior efeito residual da adubação fosfatada. Em trabalhos de pesquisa, foi mostrado que a elevação da disponibilidade de P no solo aumenta a absorção de Mg em gramíneas (Reinbott \& Blevins 1991 e 1994, Saleque et al. 2001).

Com relação à produção de biomassa seca do milheto, constatou-se que a aplicação de calcário proporcionou incrementos, independentemente da aplicação de gesso nas duas safras agrícolas (Tabela 3). A não resposta pela aplicação de gesso pode ter sido reflexo dos baixos teores de alumínio tóxico nas camadas mais profundas e aos altos teores de Ca (Tabela 1).

De acordo com Sousa \& Lobato (2004), em áreas corrigidas, com baixos teores de alumínio em subsuperfície e teores adequados de cálcio $\left(>0,5 \mathrm{cmol}_{c} \mathrm{dm}^{-3}\right)$, não é necessária a aplicação de gesso. Adicionalmente, avaliando-se os níveis de adubação aplicados à cultura anterior, constata-se que também houve efeitos significativos nos dois anos agrícolas (Figura 3), sendo que a máxima produtividade de biomassa seca foi obtida nos níveis de $125 \%$ e $150 \%$ da adubação recomendada, respectivamente nas safras 2012 e 2013. Tais resultados indicam que a produção de biomassa do milheto, no primeiro, não foi limitada pela disponibilidade de nutrientes no solo, mas, provavelmente, pelo curto período de cultivo ou deficiência hídrica (Figura 1). Esses resultados permitem inferir que lavouras adubadas adequadamente, além de proporcionarem produtividades dentro das expectativas, podem deixar resíduos de adubos passíveis de serem aproveitados pela cultura em sucessão (no caso, o milheto).

Vale ressaltar que a produção de biomassa seca do milheto foi bem inferior na safra 2012 (1.734-2.494 kg ha-1), em relação à safra 2013 $\left(2.732-3.290 \mathrm{~kg} \mathrm{ha}^{-1}\right)$. Esse resultado se deve, prova- velmente, ao fato de que, na primeira safra, o milheto cresceu e se desenvolveu por um período de 39 dias, enquanto, na segunda safra, o período foi de 52 dias.

Segundo Nascente et al. (2013a), o acúmulo de biomassa seca por plantas de cobertura é proporcional ao período de desenvolvimento, ou seja, maior período de desenvolvimento da cultura, normalmente, resulta em maior produção de matéria seca. Além disso, o período de desenvolvimento do milheto aconteceu durante o inverno, quando ocorrem baixas temperaturas e precipitação, que também afetaram significativamente o desenvolvimento da cultura (Nascente et al. 2013c).

O milheto, quando semeado entre outubro e novembro, pode acumular até $15 \mathrm{Mg} \mathrm{ha}^{-1}$ de biomassa seca, entretanto, se cultivado na safrinha, limita-se a cerca de $5 \mathrm{Mg} \mathrm{ha}^{-1}$ (Salton \& Kichel 1997, Boer et al. 2007, Pacheco et al. 2011, Nascente et al. 2013c). Entretanto, vale ressaltar que mesmo essa pequena quantidade de biomassa seca foi interessante, pois a planta acumulou nutrientes nas suas folhas, que, depois de dessecadas, podem ser aproveitadas pela cultura em sucessão.

Os resultados do presente trabalho permitem inferir que a utilização de milheto na entressafra é tecnologia viável, pois não alterou o cronograma de atividades, uma vez que foi cultivado entre a safra de soja e feijão comum, e proporciona resultados interessantes para o produtor rural, uma vez que acumulou biomassa seca, a qual, após a dessecação, ficará na superfície do solo, protegendo-o contra a erosão, conservando mais a umidade do solo e absorvendo nutrientes que estariam sujeitos a diversos processos de perdas. O custo dessa tecnologia é extremamente baixo, se resumindo à operação de semeadura e às sementes da cultura, pois o milheto aproveitou o resíduo da adubação da soja.
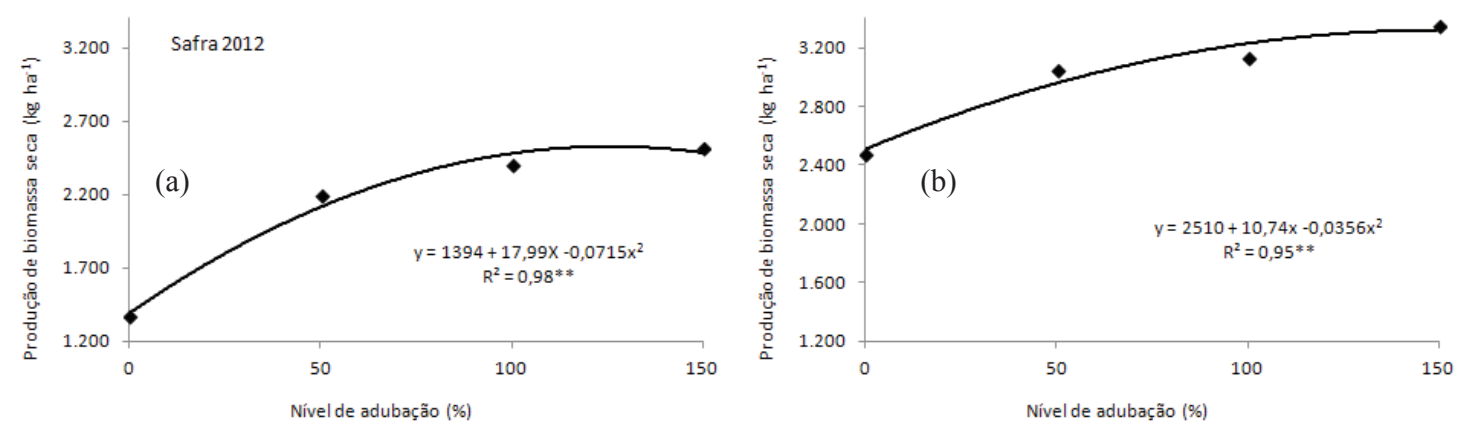

Figura 3. Produção de biomassa seca de plantas de milheto, em função dos níveis de adubação aplicados à cultura anterior (soja), nas safras 2012 (a) e 2013 (b) (Santo Antônio de Goiás, GO). 
Quando se avaliou a quantidade de nutrientes acumulados na biomassa do milheto, constatou-se que, na safra 2012, houve efeito dos corretivos no acúmulo de N, P, Mg e S (Tabela 3). Os maiores valores foram obtidos nos tratamentos com a utilização de calcário. Na safra 2013, ocorreu efeito na quantidade acumulada de $\mathrm{Ca}, \mathrm{Mg}$ e $\mathrm{S}$, sendo os menores valores obtidos no tratamento controle.

$\mathrm{O}$ aumento no acúmulo depende do aumento no teor ou na produção de biomassa, ou dos dois (Malavolta et al. 1997). Na safra 2012, os maiores valores obtidos com o uso de calcário deveram-se à maior produção de biomassa, já que os teores só aumentaram para Ca e S. Na safra 2013, o acúmulo foi influenciado, principalmente, pelo aumento nos teores de $\mathrm{Mg}$ e $\mathrm{S}$ na planta. Cálcio, $\mathrm{Mg}$ e $\mathrm{S}$ foram bastante influenciados pela sua presença no calcário e/ou no gesso. O K não foi afetado, possivelmente porque as espécies de gramíneas como o milheto, por terem baixa CTC de raízes (Ramos et al. 1977, Woodward et al. 1984, Marschner 2012), têm preferência na absorção de cátions monovalentes (Ramos et al. 1977, Woodward et al. 1984), e sua absorção não foi afetada pelo aumento na disponibilidade de $\mathrm{Ca}$ e $\mathrm{Mg}$ aplicados ao calcário. $\mathrm{O}$ acúmulo de $\mathrm{N}$ e $\mathrm{P}$ foram maiores somente devido à maior produção de biomassa. Com relação aos níveis de adubação, verificou-se que houve efeito quadrático para todos os nutrientes avaliados, nas duas safras agrícolas (Figuras 4 e 5).

Com base nos resultados, constatou-se que o aumento dos níveis de adubação na soja proporcionou incremento no conteúdo de nutrientes absorvidos pelo milheto. Dessa forma, observou-se que o milheto, em período extremamente curto (39-52 DAE), conseguiu acumular, na biomassa seca da parte aérea, 45-63 $\mathrm{kg} \mathrm{ha}^{-1}$ de N; 3-6 $\mathrm{kg} \mathrm{ha}^{-1}$ de P; 57-97 $\mathrm{kg} \mathrm{ha}^{-1}$ de $\mathrm{K}$; 9-13 kg ha ${ }^{-1}$ de Ca; 3-6 $\mathrm{kg} \mathrm{ha}^{-1}$ de Mg; e 3-5 $\mathrm{kg} \mathrm{ha}^{-1}$ de $\mathrm{S}$. Essas quantidades consideráveis de nutrientes ficam protegidas dos diversos processos de perdas no solo e podem ser aproveitadas pela cultura em
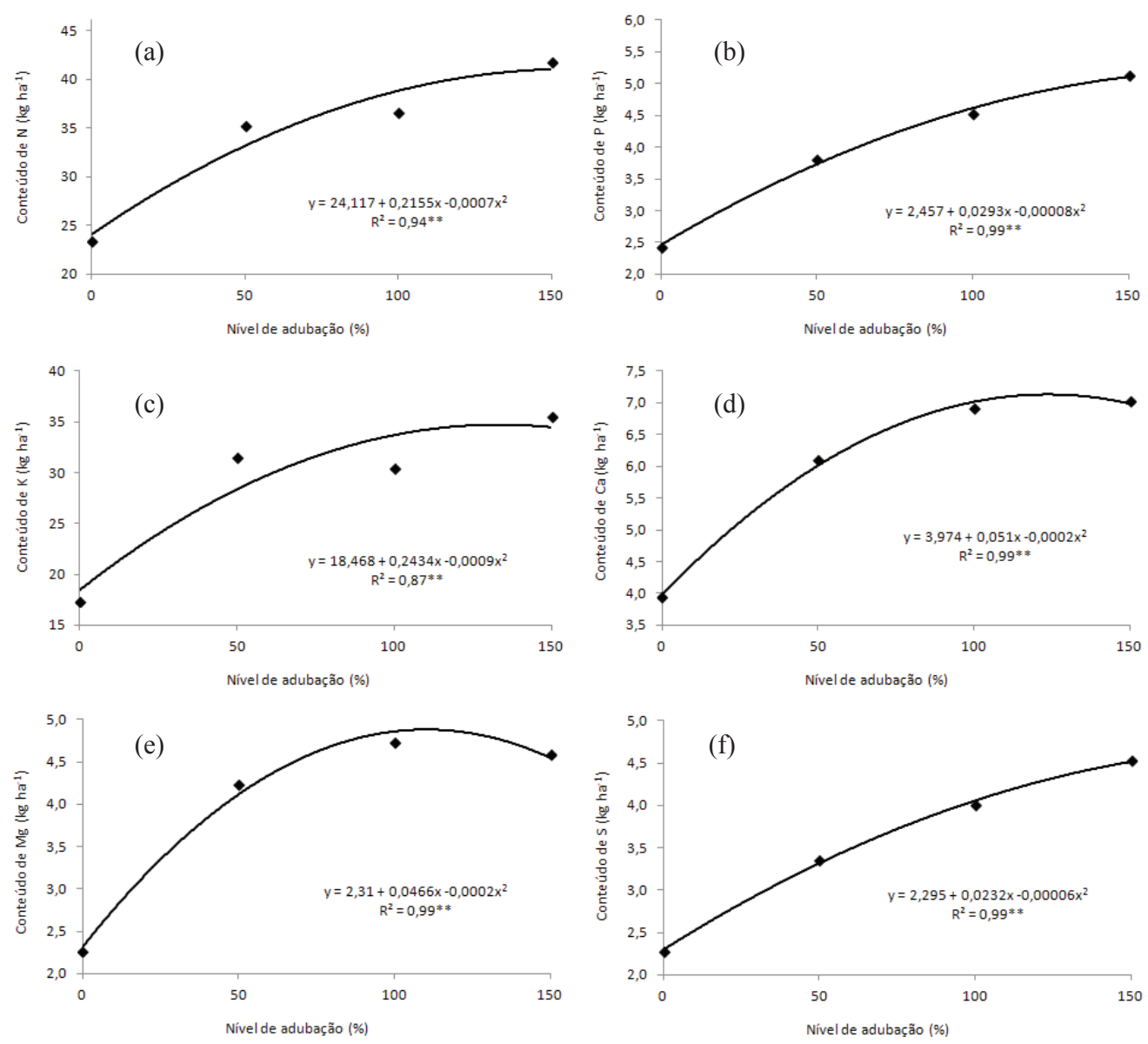

Figura 4. Quantidade acumulada de N (a), P (b), K (c), Ca (d), Mg (e) e S (f) na biomassa seca de plantas de milheto, em função dos níveis de adubação aplicados à cultura anterior (soja) (Santo Antônio de Goiás, GO, safra 2012). 

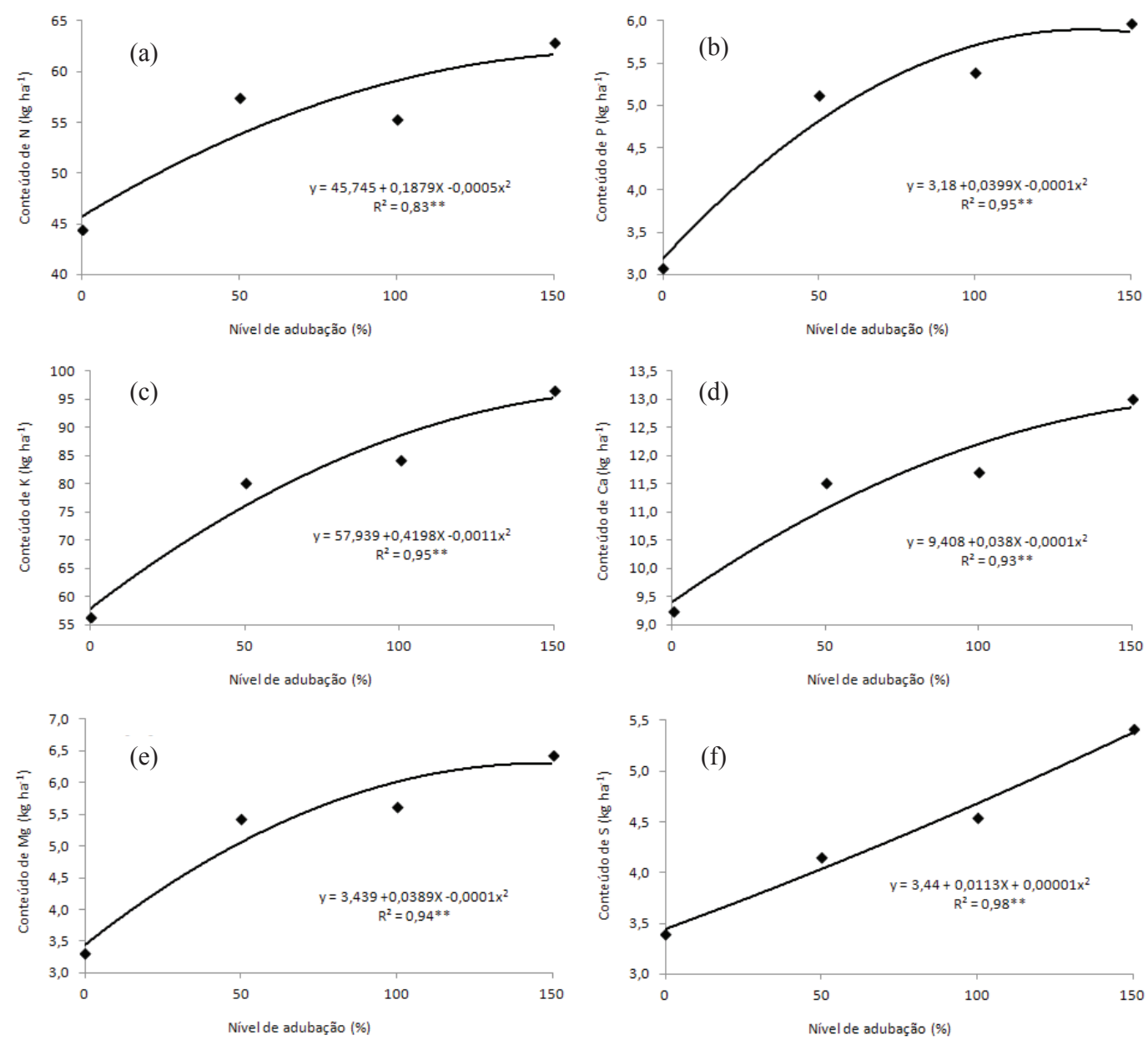

Figura 5. Quantidade acumulada de N (a), P (b), K (c), Ca (d), Mg (e) e S (f) em plantas de milheto, em função dos níveis de adubação aplicados à cultura anterior (soja) (Santo Antônio de Goiás, GO, safra 2013).

sucessão, à medida em que forem mineralizadas, após a dessecação do milheto.

Assim, o milheto apresenta características interessantes para ser utilizado como planta de cobertura, por possuir, provavelmente, sistema radicular profundo e vigoroso, o que proporcionou grande ciclagem de nutrientes, em curto período de tempo. Essas características são importantes, principalmente em solos de baixa fertilidade, como é o caso dos encontrados na Região dos Cerrados (Boer et al. 2007, Timossi et al. 2007, Carpim et al. 2008, Foloni et al. 2008, Cunha et al. 2010, Pacheco et al. 2011, Nascente et al. 2013a).

\section{CONCLUSÕES}

1. A aplicação de calcário proporcionou melhoria na nutrição de plantas e na produção de biomassa seca do milheto.
2. A aplicação de gesso não causou alterações na produção de biomassa seca do milheto, embora tenha aumentado a concentração de enxofre nas plantas.

3. A utilização de doses crescentes de fertilizantes (superfosfato simples, superfosfato triplo e cloreto de potássio), na cultura anterior (soja), resultou em aumentos na produção de biomassa seca, concentração e acúmulo de nutrientes nas plantas de milheto.

4. A utilização de milheto como planta de cobertura na entressafra, utilizando o efeito residual do fertilizante aplicado à cultura de verão, proporcionou ciclagem de nutrientes que pode ser utilizada pela cultura em sucessão.

\section{REFERÊNCIAS}

AITA, C.; GIACOMINI, S. J. Decomposição e liberação de nitrogênio de resíduos culturais de plantas de cobertura 
de solo solteiras e consorciadas. Revista Brasileira de Ciência do Solo, Viçosa, v. 27, n. 4, p. 601-612, 2003.

ALVARENGA, R. C. et al. Plantas de cobertura de solo para sistema de plantio direto. Informe Agropecuário, Belo Horizonte, v. 22, n. 1, p. 25-36, 2001.

BOER, C. A. et al. Ciclagem de nutrientes por plantas de cobertura na entressafra em um solo de Cerrado. Pesquisa Agropecuária Brasileira, Brasília, DF, v. 42, n. 9, p. 12691276, 2007.

CAIRES, E. F. et al. Alterações de características químicas do solo e resposta da soja ao calcário e gesso aplicados na superfície em sistema de cultivo sem preparo do solo. Revista Brasileira de Ciência do Solo, Viçosa, v. 22, n. 1, p. 27-34, 1998.

CAIRES, E. F. et al. Alterações químicas do solo e resposta da soja ao calcário e gesso aplicados na implantação do sistema plantio direto. Revista Brasileira de Ciência do Solo, Viçosa, v. 27, n. 2, p. 275-286, 2003.

CAIRES, E. F. et al. Effects of soil acidity amelioration by surface liming on no-till corn, soybean, and wheat root growth and yield. European Journal of Agronomy, Amsterdan, v. 28, n. 1, p. 57-64, 2008.

CARPIM, L. K. et al. Liberação de nutrientes pela palhada de milheto em diferentes estádios fenológicos. Revista Brasileira de Ciência do Solo, Viçosa, v. 32, n. esp., p. 2813-2819, 2008.

CARVALHO, M. C. S.; NASCENTE, A. S. Limestone and phosphogypsum effects on soil fertility, soybean leaf nutrition and yield. African Journal of Agricultural Research, Lagos, v. 9, n. 17, p. 1366-1383, 2014.

CARVALHO, M. C. S.; RAIJ, B. V. Calcium sulphate, phosphogypsum and calcium carbonate in the amelioration of acid subsoils for root growth. Plant and Soil, The Hague, v. 192, n. 1, p. 37-48, 1997.

CLAESSEN, M. E. C. Manual de métodos de análise de solo. 2. ed. Rio de Janeiro: Embrapa-CNPS, 1997.

COSTA, A.; ROSOLEM, C. A. Liming in the transition to no-till under a wheat-soybean rotation. Soil and Tillage Research, Amsterdam, v. 97, n. 2, p. 207-217, 2007.

COSTA, C. H. M. et al. Persistência e liberação de macronutrientes e silício da fitomassa de crotalária em função da fragmentação. Bioscience Journal, Uberlândia, v. 28, n. 3, p. 384-394, 2012.

CRUSCIOL, C. A. C. et al. An innovative crop-forage intercrop system: early cycle soybean cultivars and palisadegrass. Agronomy Journal, Madison, v. 104, n. 4, p. 1085-1095, 2012.

CUNHA, P. C. R. et al. Atributos químicos de solo cultivado com diferentes culturas de cobertura. Pesquisa
Agropecuária Tropical, Goiânia, v. 40, n. 3, p. 283-290, 2010.

FAVERO, C. et al. Crescimento e acúmulo de nutrientes por plantas espontâneas e por leguminosas utilizadas para adubação verde. Revista Brasileira de Ciência do Solo, Viçosa, v. 24, n. 1, p. 171-177, 2000.

FERRARI NETO, J. et al. Consórcio de guandu-anão com milheto: persistência e liberação de macronutrientes e silício da fitomassa. Bragantia, Campinas, v. 71, n. 2, p. 264-272, 2012.

FOLONI, J. S. S. et al. Aplicação de fosfato natural e reciclagem de fósforo por milheto, braquiária, milho e soja. Revista Brasileira de Ciência do Solo, Viçosa, v. 32, n. 3, p. 1147-1155, 2008.

FOOD AND AGRICULTURE ORGANIZATION OF THE UNITED NATIONS (FAO). Conservation agriculture adoptions worldwide. 2012. Disponível em: $<$ http://www. fao.org/ag/ca/6c.html >. Acesso em: 10 out. 2013.

MALAVOLTA, E. et al. Avaliação do estado nutricional de plantas: princípios e aplicações. 2. ed. Piracicaba: Potafos, 1997.

MARSCHNER, H. Mineral nutrition of higher plants. 3. ed. London: Academic Press, 2012.

MAULI, M. M. et al. Variation on the amount of winter cover crops residues on weeds incidence and soil seed bank during an agricultural year. Brazilian Archives of Biology and Technology, Curitiba, v. 54, n. 4, p. 683-690, 2011.

NASCENTE, A. S.; CRUSCIOL, C. A. C. Cover crops and herbicide timing management on soybean yield under notillage system. Pesquisa Agropecuária Brasileira, Brasília, DF, v. 47, n. 2, p. 187-192, 2012.

NASCENTE, A. S. et al. Interferência das plantas daninhas na cultura do tomate para processamento. Horticultura Brasileira, Brasília, DF, v. 22, n. 3, p. 602-606, 2004.

NASCENTE, A. S. et al. Produtividade do arroz de terras altas em função do manejo do solo e da época de aplicação de nitrogênio. Pesquisa Agropecuária Tropical, Goiânia, v. 41, n. 1, p. 60-65, 2011.

NASCENTE, A. S. et al. The no-tillage system and cover crops: alternatives to increase upland rice yields. European Journal of Agronomy, Amsterdam, v. 45, n. 2, p. 124-131, 2013a.

NASCENTE, A. S. et al. Cover crops and no-till effects on physical fractions of soil organic matter. Soil and Tillage Research, Amsterdam, v. 130, n. 6, p. 52-57, 2013 b.

NASCENTE, A. S. et al. Cover crop termination timing on rice crop production in a no-till system. Crop Science, Madison, v. 53, n. 6, p. 2659-2669, 2013c. 
PACHECO, L. P. et al. Produção de fitomassa e acúmulo e liberação de nutrientes por plantas de cobertura na safrinha. Pesquisa Agropecuária Brasileira, Brasília, DF, v. 46, n. 1, p. 17-25, 2011.

QUAGGIO, J. A. et al. Respostas da soja à aplicação de calcário e gesso e lixiviação de íons no perfil do solo. Pesquisa Agropecuária Brasileira, Brasília, DF, v. 28, n. 3, p. 375-383, 1993.

RAMOS, G. M. et al. Determinação da capacidade de troca catiônica das raízes de plantas forrageiras e sua relação com os teores de potássio, de cálcio e de magnésio na parte aérea. Revista Ceres, Viçosa, v. 24, n. 135, p. 515$520,1977$.

REINBOTT, T. M.; BLEVINS, D. G. Phosphate interaction with uptake and leaf concentration of magnesium, calcium, and potassium in winter wheat "seedlings". Agronomy Journal, Madison, v. 83, n. 6, p. 1043-1046, 1991.

REINBOTT, T. M.; BLEVINS, D. G. Phosphorus and temperature effects on magnesium, calcium, and potassium in wheat and tall fescue leaves. Agronomy Journal, Madison, v. 86, n. 3, p. 523-529, 1994.

ROSOLEM, C. A.; MARCELLO, C. S. Crescimento radicular e nutrição mineral da soja em função da calagem e adubação fosfatada. Scientia Agricola, Piracicaba, v. 55, n. 3, p. 448-455, 1998.

SALEQUE, M. A. et al. Influences of phosphorus deficiency on the uptake of nitrogen, potassium, calcium, magnesium, sulfur, and zinc in lowland rice varieties. Journal of Plant Nutrition, New York, v. 24, n. 10, p. 16211632, 2001.
SALTON, J. C.; KICHEL, A. N. Milheto: alternativa para cobertura do solo e alimentação animal. Dourados: Embrapa Agropecuária Oeste, 1997. 1 folder.

SILVA, T. R. B.; LEMOS, L. B. Efeito da calagem superficial em plantio direto na concentração de cátions hidrossolúveis na parte aérea de culturas anuais. Revista Brasileira de Ciência do Solo, Viçosa, v. 32, n. 3, p. 11991207, 2008.

SILVA, N. M. et al. Efeitos do calcário e do gesso nas características químicas do solo e na cultura do algodão. Bragantia, Campinas, v. 56, n. 2, p. 389-401, 1997.

SOUSA, D. M. G. de; LOBATO, E. (Eds.). Cerrado: correção do solo e adubação. 2. ed. Brasília, DF: Embrapa, 2004.

TIMOSSI, P. C. et al. Formação de palhada por braquiárias para adoção do sistema plantio direto. Bragantia, Campinas, v. 66, n. 4, p. 617-622, 2007.

TORRES, J. L. R. et al. Produção de fitomassa por plantas de cobertura e mineralização de seus resíduos em plantio direto. Pesquisa Agropecuária Brasileira, Brasília, DF, v. 43, n. 3, p. 421-428, 2008.

VERONESE, M. et al. Cover crops and liming in the implementation of no-tillage system. Pesquisa Agropecuária Brasileira, Brasília, DF, v. 47, n. 8, p. 1158$1165,2012$.

WOODWARD, R.; HARPER, K.; TIEDEMANN, A. An ecological consideration of the significance of cationexchange capacity of roots of some Utah range plants. Plant and Soil, The Hague, v. 79, n. 2, p. 169-180, 1984. 